\title{
Delayed endometrial decidualisation in polycystic ovary syndrome; the role of AR-MAGEA11
}

\author{
Kinza Younas $^{1,2} \cdot$ Marcos Quintela $^{1} \cdot$ Samantha Thomas ${ }^{1} \cdot$ Jetzabel Garcia-Parra ${ }^{1} \cdot$ Lauren Blake $^{1} \cdot$ Helen Whiteland $^{1}$. \\ Adnan Bunkheila $^{1,2} \cdot$ Lewis W. Francis $^{1} \cdot$ Lavinia Margarit $^{1,2} \cdot$ Deyarina Gonzalez $^{1} \cdot$ R. Steven Conlan $^{1}$ (D)
}

Received: 23 March 2019 /Revised: 22 May 2019 / Accepted: 2 June 2019 / Published online: 29 June 2019

(C) The Author(s) 2019

\begin{abstract}
Polycystic ovary syndrome (PCOS) is a common gynaecological disorder, with a prevalence of up to $12 \%$ of women of reproductive age, and is in part characterised by elevated circulating androgens and aberrant expression of androgen receptor (AR) in the endometrium. A high percentage of PCOS patients suffer from infertility, a condition that appears to be linked to mistimed and incomplete decidualisation critically affecting events surrounding embryo implantation. The aim of this study was to examine the involvement of MAGEA11, and the genome-wide role of AR in PCOS. We determined that elevated androgen levels on PCOS cells had an impact on the delayed and incomplete decidual transformation of endometrial cells. The AR co-regulator MAGEA11, a known enhancer of AR function, was constitutively overexpressed throughout the menstrual cycle of PCOS patients, co-localised in the nucleus of PCOS stromal tissue and cells and formed a molecular complex with AR. Genome-wide AR analysis in PCOS stromal cells revealed that AR targets included genes involved in cell death and apoptosis, as well as genes commonly dysregulated in endometrial cancer. Enhanced MAGEA11 and AR-mediated transcriptional regulation may impact on a correct endometrial decidualisation response, subsequently affecting endometrial receptivity in these infertile women.
\end{abstract}

\section{Key messages}

- MAGEA11 and AR are overexpressed in hyperandrogenic PCOS patients.

- MAGEA11-AR overexpression in PCOS correlates with delayed decidualisation.

- AR and MAGEA11 associate in a molecular complex.

- AR directly regulates a unique set of genes controlling gene differentiation.

Keywords PCOS $\cdot$ AR $\cdot$ MAGEA11 $\cdot$ Decidualisation $\cdot$ Delay

\section{Introduction}

Polycystic ovary syndrome (PCOS) is a common gynaecological disorder affecting 4-12\% of reproductive age

Kinza Younas and Marcos Quintela contributed equally to this work.

Electronic supplementary material The online version of this article (https://doi.org/10.1007/s00109-019-01809-6) contains supplementary material, which is available to authorized users.

R. Steven Conlan

r.s.conlan@swansea.ac.uk

1 Reproductive Biology and Gynaecological Oncology, Swansea University Medical School, Singleton Park, Swansea SA2 8PP, UK

2 Abertawe Bro Morgannwg University Health Board, Sketty Lane, Swansea SA2 8QA, UK women. Up to $44 \%$ of unexplained infertility cases display a PCOS morphology linked with ovulatory dysfunction and systemic hyperandrogenaemia. PCOS patients accumulate androgens due to defects in aromatase activity that prevents the conversion of androgens to oestrogens [1]. Despite ovulation, a proportion of PCOS patients remain infertile suggesting an important role for endometrial receptivity, orchestrated by embryo implantation and decidualisation, a phenomenon that involves dramatic morphological and functional differentiation of human endometrial stromal cells (hESCs) [2, 3]. In addition, endometrial cells from women treated with androgens exhibit altered growth and differentiation in vitro suggesting a potential decidualisation defect in PCOS patients [4].

Previously, we have shown that levels of apoptosis are reduced in stromal cells in both ovulatory PCOS and androgentreated fertile samples [4]. This is accompanied by increased 
levels of anti-apoptotic factors Bcl2 and p27, and dramatic reductions in EGFR and WT1 expression in response to androgens [4]. Such alterations may contribute to the dysregulation of differentiation and cell cycle, thereby compromising the reproductive potential of PCOS patients [4].

The effects of androgens are mediated through androgen receptors (AR), nuclear hormone receptors that bind to and regulate the expression of specific target genes. AR functions through interactions with co-regulator proteins that result in the repression or activation of target gene transcription through modification of chromatin structure and regulation of RNA polymerase activity [5]. AR co-regulator proteins include MAGEA11, which has been shown to physically associate with the nuclear receptor in vitro [6, 7]. MAGEA family members are involved in the regulation of apoptosis, cell cycle progression, cellular differentiation, and proliferation [8-10]. Endometrial MAGEA11 expression has been shown in the secretory phase of the menstrual cycle in fertile women [11]. In vitro experiments demonstrated a progesterone receptor (PR) isoform B specific requirement for MAGEA11 in the activation of progesterone-regulated genes [7]. In prostate cancer, MAGEA11 is an androgen responsive gene and, following exposure of cells to androgens, co-localises to the nucleus with AR, where it functions as an AR co-regulator increasing AR transcriptional activity [12].

Here, we show that the addition of androgens disrupts the differentiation of endometrial stromal cells during the process of decidualisation in vitro. This process is accompanied by increases in the expression of MAGEA11, which is recapitulated in the endometrium of PCOS patients. Following treatment with dihydrotestosterone (DHT), both MAGEA11 and AR accumulate and co-localise in the nucleus both in vitro and in vivo in endometrial tissues obtained from PCOS patients. Genome-wide analysis of AR interactions using chromatin immunoprecipitation revealed that AR interacts with genes involved in the regulation of cell death and apoptosis including EGFR and WT1, supporting the notion that elevated androgens result in delayed decidualisation processes, and implicating AR and MAGEA11 in incorrect endometrial differentiation. This could impact on the critical timing process of embryo implantation, and thus human reproduction.

\section{Materials and methods}

\section{Stromal cell isolation}

Primary endometrial stromal cells (ESCs) were isolated from endometrial biopsies as previously described [4], yielding a 95\% pure stromal cell culture [13]. ESCs $\left(6 \times 10^{5}\right.$ cells) were cultured in 6-well plates for $24 \mathrm{~h}$ prior to treatments. Confluent ESC monolayers were treated with cAMP $(500 \mu \mathrm{M}$, A6885, Sigma, UK), DHT $\left(10^{-8} \mathrm{M}, \mathrm{A} 8380\right.$, Sigma), and DHT +
cAMP $\left(10^{-8} \mathrm{M}+500 \mu \mathrm{M}\right)$ for $24 \mathrm{~h}, 48 \mathrm{~h}$, and $72 \mathrm{~h}$. RNA was extracted after treatments and cell morphology assessed throughout the duration of the experiment.

\section{Morphological analysis}

Primary cells were washed in PBS and fixed for $15 \mathrm{~min}$ in $4 \%$ paraformaldehyde buffered in $0.1 \mathrm{M}$ sodium cacodylate (pH 7.2). Standard light microscope images (Zeiss Axiovert ${ }^{\mathrm{TM}}$, UK) were captured and shape index was used to calculate changes in cell shape. ImageJ software was used to calculate the circularity of the cells and this was performed as previously described [14]. A perfect circle (indicating a decidualised cell) has a shape index of one while a straight line (indicating a nondecidualised stromal cell) has a shape index of zero.

\section{Enzyme-linked immune-sorbent assays}

Human prolactin/IGFBP-1 DuoSet ELISA kits (DY682/ DY871, R\&D Systems, MN, USA) were used to analyse the presence of prolactin/IGFBP-1 in cell culture media. The target medium was collected from confluent monolayers of ESC cells treated for $48 \mathrm{~h}$ with cAMP and DHT. The protocols were performed as per manufacturer's instructions and each sample was measured in triplicates.

\section{Patient samples}

Patient recruitment and consent was carried out at the gynaecology clinics at Singleton Hospital, Swansea. Endometrial biopsies from women in a natural menstrual cycle were obtained for immunohistochemistry and in vitro studies. Patients had not received exogenous hormonal therapy at least two months before the procedure. Women with systemic diseases, sexually transmitted infections, or evidence of endometritis, endometrial hyperplasia, or endometrial polyp were excluded. The presence of chronic endometritis was ruled out by immunohistochemical analysis of biopsy samples. The phase of the natural menstrual cycle was confirmed by ultrasound and histological criteria; urinary luteinising hormone (LH) was used to document ovulation. The control group included women with proven fertility and regular menstrual cycles. The study group consisted of infertile women with PCOS; patients in control and study groups were matched with regard to body mass index (BMI) and smoking habits. PCOS was diagnosed based on the Rotterdam criteria of ultrasound and clinical and biochemical features of hyperandrogenism [15]. Anovulatory PCOS patients were oligomenorrhoeic or amenorrhoeic, and biochemical and clinical examinations confirmed the lack of ovulation. The ovulatory PCOS patients had confirmed polycystic ovaries on ultrasound, hyperandrogenism, and ovulated spontaneously with serum progesterone levels measured at $\mathrm{LH}+$ seven at least $30 \mathrm{~nm} / \mathrm{l}$, were nulliparous despite regular 
ovulatory cycles in the presence of patent tubes, and sperm parameters were normal. Blood samples were collected from patients at day two of the menstrual cycle for assessment of hormone levels using the electrochemiluminescence immunoassays (Elecsys ${ }^{\circledR}$ assays and Elecsys ${ }^{\circledR} 2010$ immunoassay analyser, Roche) for progesterone, follicle stimulating hormone (FSH), luteinising hormone (LH), and testosterone, as well as radio-immunoassays (RIA, Beckman Coulter), to measure androstenedione. Endometrial biopsies were obtained by Pipelle endometrial sampling or by curettage concurrent to diagnostic laparoscopy; samples were divided in two groups for immunohistochemistry and in vitro studies.

A total of 116 patients were enrolled in the study, 51 of proven fertility and 65 infertile. Endometrial samples were obtained from 58 patients in the secretory phase [fertile $(n=33)$, infertile ovulatory PCOS (ovPCOS, $n=$ 25)] and 37 patients in the proliferative phase. [fertile $(n=18)$, infertile ovPCOS $(n=19)]$. Endometrial samples were also taken from 21 PCOS women who were anovulatory (anovPCOS). There were no statistically significant differences in the mean age or body mass index between the groups (Table 1). Both PCOS groups exhibited statistically higher levels of serum testosterone compared with the fertile group (Table 1).

\section{Immunohistochemistry}

Preparation of formalin-fixed paraffin-embedded (FFPE) samples, nuclei-staining, and immunohistochemistry was performed as previously described [16]. Positive (tonsil) and negative (endometrium) tissue sections were used as controls. Rabbit polyclonal antibodies for anti-MAGEA11 (T1241, Epitomics ${ }^{\circledR}$, California, USA) and for anti-AR (N-20, Santa Cruz $®$, California, USA) were used (1/50). Slides were evaluated using the $\mathrm{H}$-scoring system by three independent scorers blinded to patient diagnosis, demographics, and timing of biopsy [16].

\section{RNA isolation and qRT-PCR}

RNA isolation, quantification, and qRT-PCR analysis using gene-specific primer-pairs (available on request) were performed as previously described [4]. Expression levels were normalised to an internal reference gene (GAPDH). Expression was calculated as a ratio between treated and control samples for each gene. Densitometry analyses were performed using Image Lab software (BioRad, UK).

\section{Immunofluorescence confocal microscopy}

ESCs $\left(2 \times 10^{5}\right.$ cells $)$ were grown to $80 \%$ confluence on 8 -well chambered borosilicate coverglass (Thermo Scientific Ltd., UK). At $24 \mathrm{~h}$ post induction of decidualisation (+DHT), cells were fixed with $4 \%$ paraformaldehyde, permeabilised with $0.1 \%$ Triton X-100 (Sigma), and blocked with 3\% BSA in PBS for $1 \mathrm{~h}$. Primary antibodies, anti-AR (ab9474, Abcam ${ }^{\circledR}$, Massachusetts, USA), and anti-MAGEA11 (ab60043, Abcam ${ }^{\circledR}$ ) diluted in 3\% BSA PBS were incubated overnight at $4{ }^{\circ} \mathrm{C}$, followed by $1 \mathrm{~h}$ incubation with secondary antibodies, Alexa488 (green, mouse anti-AR) and Alexa TexasRed (red, rabbit anti-MAGEA11). Cells were washed with PBS extensively between all steps, counterstained before imaging with NucBlue reagent (Life Technologies) and imaged using an LSM710 confocal fluorescence microscopy system (Zeiss, UK).

\section{Protein blotting and co-immunoprecipitation}

Protein blotting was performed as previously described [14]. For co-immunoprecipitation, PCOS stromal cells were grown to confluency and subsequently exposed to $0.1 \mu \mathrm{M}$ DHT for $24 \mathrm{~h}$ before cells were fixed with $4 \%$ paraformaldehyde in order to stabilise protein complexes. Total protein was extracted using RIPA buffer and pre-cleared by rotation with A/G PLUS-Agarose beads (sc-2003, Santa Cruz). The lysate was subjected to anti-AR antibody (ab9474, mouse monoclonal)

Table 1 Patient demographics

\begin{tabular}{lccc}
\hline & Fertile $(n=51)$ & Ovulatory PCOS $(n=44)$ & Anovulatory PCOS $(n=21)$ \\
\hline Age & $30 \pm 4.6$ & $29.0 \pm 5.0(p=0.728)$ & $29.1 \pm 2.6(p=0.562)$ \\
Body mass index $\left(\mathrm{BMI}, \mathrm{kg} / \mathrm{m}^{2}\right)$ & $26.8 \pm 4.9$ & $29.1 \pm 5.0(p=0.520)$ & $32.3 \pm 5.8(p=0.076)$ \\
Progesterone $(\mathrm{ng} / \mathrm{mL})$ & $31 \pm 5.28$ & $27.45 \pm 11.5(p=0.597)$ & $\mathrm{N} / \mathrm{A}$ \\
$\mathrm{FSH}(\mathrm{mUI} / \mathrm{mL})$ & $7.4 \pm 3.017$ & $5.67 \pm 1.37(p=0.135)$ & $5.34 \pm 2.57(p=0.2041)$ \\
$\mathrm{LH}^{2}(\mathrm{mUI} / \mathrm{mL})$ & $4.90 \pm 2.221$ & $12.70 \pm 4.27(p=0.0004)$ & $15.63 \pm 4.94(p=0.0008)$ \\
Total testosterone $(\mathrm{nmol} / \mathrm{L})$ & $0.76 \pm 0.472$ & $1.72 \pm 0.313(p=0.1)$ & $2.94 \pm 0.108(p=0.001)$ \\
Free testosterone $(\mathrm{nmol} / \mathrm{L})$ & $13.13 \pm 6.12$ & $18.5 \pm 5.7(p=0.08)$ & $37.15 \pm 10.6(p=0.002)$ \\
Androstenedione $(\mathrm{nmol} / \mathrm{L})$ & $3.43 \pm 0.23$ & $7.70 \pm 1.6(p=0.006)$ & $8.72 \pm 1.1(p=0.0001)$ \\
\hline
\end{tabular}

${ }^{1} \mathrm{FSH}$ follicle stimulating hormone

${ }^{2}$ LH luteinising hormone 
$\mathrm{O} / \mathrm{N}$ incubation $\left(4^{\circ} \mathrm{C}\right)$, followed by another incubation with A/G PLUS-Agarose beads ( $2 \mathrm{~h}$ ). After several washing steps, the samples were separated by SDS-PAGE and probed using an anti-MAGEA11 antibody (T1241, rabbit polyclonal).

\section{Chromatin immunoprecipitation and DNA sequencing}

PCOS ESCs $\left(1.2 \times 10^{6}\right.$ cells) were cultured in $75-\mathrm{cm}^{2}$ flasks for $24 \mathrm{~h}$ prior to DHT treatment $(48 \mathrm{~h})$. DHT-treated PCOS ESC cells were then fixed using $1 \%$ formaldehyde solution (Sigma ${ }^{\circledR}$ ), quenched with $2.5 \mathrm{M}$ Glycine (Sigma ${ }^{\circledR}$ ), and centrifuged following Active Motif's Epigenetic Services ChIP Cell Fixation Protocol instructions. The resulting pellet was sent to Active Motif $\circledast$ for sequencing, alongside with an antiAR antibody (ab9474), which was used to probe for AR-target region enrichment. Raw ChIP-seq data is deposited in the GEO Dataset, with accession number GSE119432.

\section{MEME-Suite}

FASTA data files obtained from the AR ChIP-seq performed on PCOS tissue were loaded onto the MEME-Suite. First, the sequence analysis tool DREME (Bailey 2011) was used to discover relatively enriched motifs, comparing the AR ChIPseq sequences with control shuffle sequences. Next, the motif comparison tool Tomtom (Gupta et al. 2007) was used to compare the DREME-enriched motifs against a database of known motifs, providing a list of matches and their correspondent $p$ values.

\section{Analysis of the ChIP-seq data and Venn diagram}

Alongside with the correspondent FASTA files, Active Motif® provided a list of 2798 genes. In most cases, the gene sequence encompassed the associated ChIP-seq peak location, although some upstream or downstream peaks were linked to gene targets through the identification of nearby promoters. Each gene was associated with a peak value, an average of peak values in case the gene contains several peaks, which were filtered to obtain a list of 577 high-intensity peaks (peak value $>20$ ). The list of 577 high-intensity peaks was compared with a list of AR binding sites in human prostate cancer tissues (Sharma et al. 2013) using a Venn diagram (Hulsen et al. 2008).

\section{Genomic Regions Enrichment of Annotations Tool}

The filtered genomic localisation of 6296 AR-PCOS peaks (peak value $>20$ ) was loaded onto Genomic Regions Enrichment of Annotations Tool (GREAT) (McLean et al. 2010) in order to analyse the functional significance of ChIP-seq-identified cis-regulatory regions (gene ontology).

\section{Statistical analyses}

Data distributions were assessed for normality using the Kolmogorov Smirnov test. Non-normally distributed data was analysed with the Mann-Whitney $U$ test applied in a post hoc to determine statistical significance. For normally distributed data, an ANOVA test followed by a $t$ test was used to determine significant differences between groups. The test statistic and corresponding $p$ value were reported. All data analyses were performed using SPSS version 13.0 (SPSS, Illinois, USA).

\section{Results}

\section{Mesenchymal to epithelial transition is blocked in PCOS stromal cells}

Decidual transformation involves a mesenchymal to epithelial (MET)-like phenotypic transition in hESC in response to cyclic AMP (cAMP) in a normal menstrual cycle [17]. We assessed hESC isolated from primary tissue samples for a decidual response by calculating the cell shape index for MET. Cell shape index is a dimensionless quantitative measure of cell morphology acquired from standard light microscope images [18]. Following an initial exposure to cAMP to trigger differentiation, stromal cells underwent a rapid MET transition, morphologically transitioning from elongated to rounded cells with the calculated shape index approaching one (Fig. 1a and Supplementary Fig. 1). The MET-like response was initiated within the first $24 \mathrm{~h}$ following cAMP treatment and was sustained over the duration of the experiment, demonstrating that cAMP could effectively stimulate the transition. This observed MET-like effect was not impaired when fertile cells were simultaneously treated with cAMP and DHT, demonstrating that MET in fertile cells is unaffected by DHT. In contrast, cells derived from PCOS biopsies exhibited a delayed and only partial shape transition (Fig. 1b). After $24 \mathrm{~h}$ the shape index was 0.3 , and increased slowly up to a maximum of 0.5 after $72 \mathrm{~h}$ in response to cAMP. When cAMP and DHT were used in combination in PCOS cells, the extent of the MET-like response remained partial, with a shape index of 0.3 at each time points (Fig. 1b).

Prolactin and IGFBP-1 are known indicators of MET in the context of hESC [17]; accordingly, the expression of these markers was quantified using enzyme-linked immune-sorbent assays (ELISA) (Fig. 1c, d). In fertile cells, prolactin and IGFBP-1 levels were significantly increased following exposure to cAMP (prolactin: $p<0.01$; IGFBP-1: $p=0.025$ ) and cAMP + DHT (prolactin: $p=0.03$; IGFBP-1: $p<0.01$ ). In accordance with the morphological response observed in PCOS patients (Fig. $1 \mathrm{~b})$, PCOS cells exhibited a limited upregulation of 


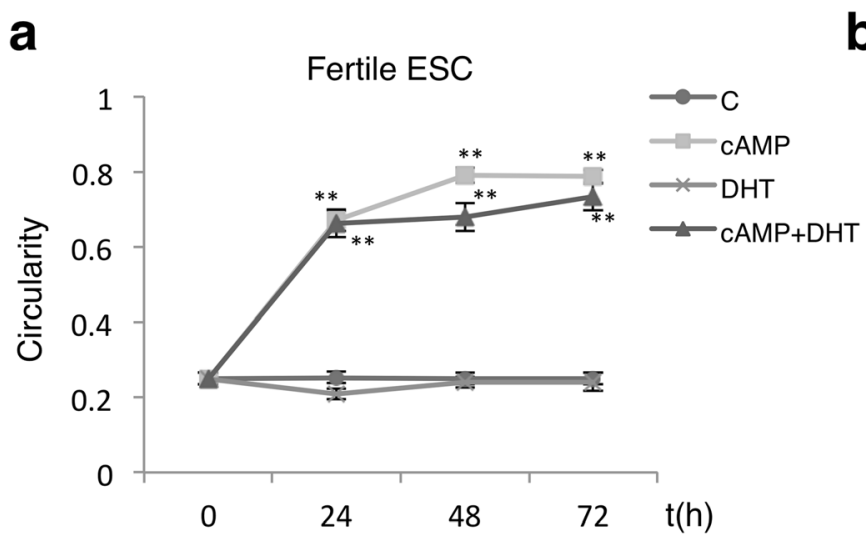

C
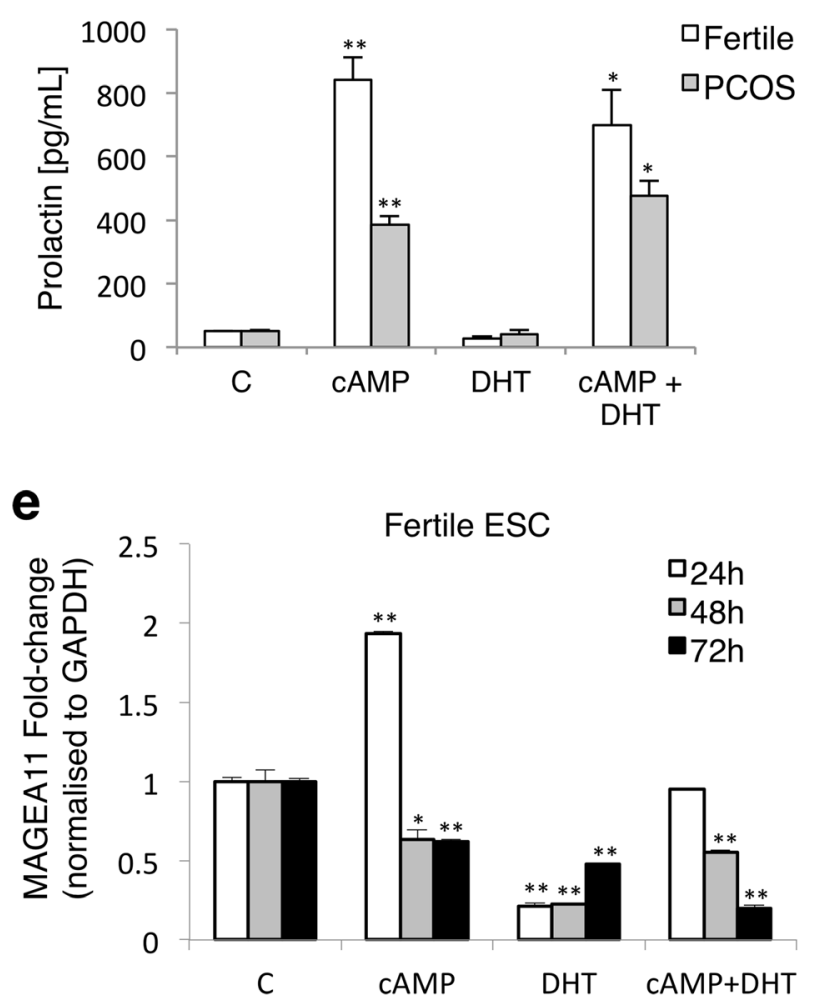

Fig. 1 Regulation of MAGEA11 expression in ESC during in vitro decidualisation. Endometrial stromal cells (ESC) isolated from biopsies of fertile $(n=8)$ and PCOS $(n=9)$ patients were left untreated (C), incubated with cyclic AMP (cAMP, $0.5 \mathrm{mM}$ ), dihydrotestosterone (DHT, $10^{-6} \mathrm{M}$ ) or a combination of both for 24 to $72 \mathrm{~h}$. ESCs were obtained from cells in the secretory phase of the cycle. Cell morphology was recorded throughout the experiment to document decidual changes. a, b ESC shape changes were assessed as described in the "Materials and Methods" section. ImageJ software was used to calculate the circularity of the cells ( $n=20$ /group), with a perfect circle having a value of one, while a straight line has a circularity value of zero. $\mathbf{c}, \mathbf{d}$ Cell media was b

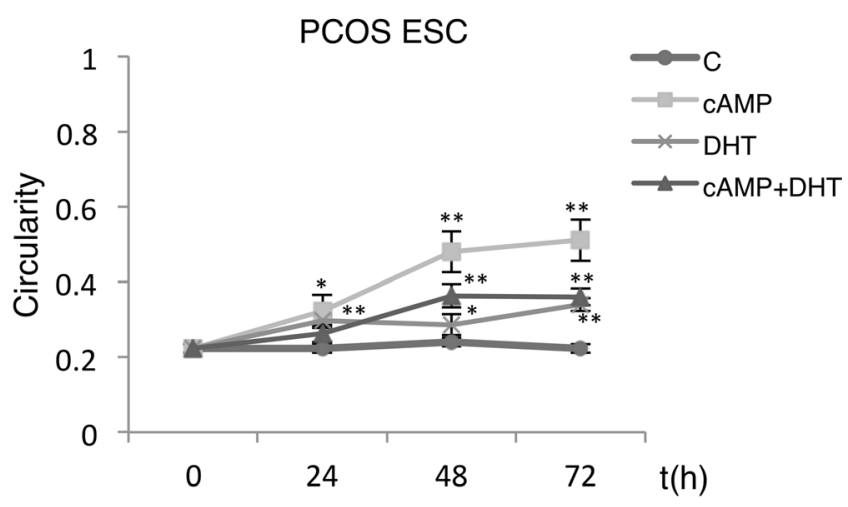

d

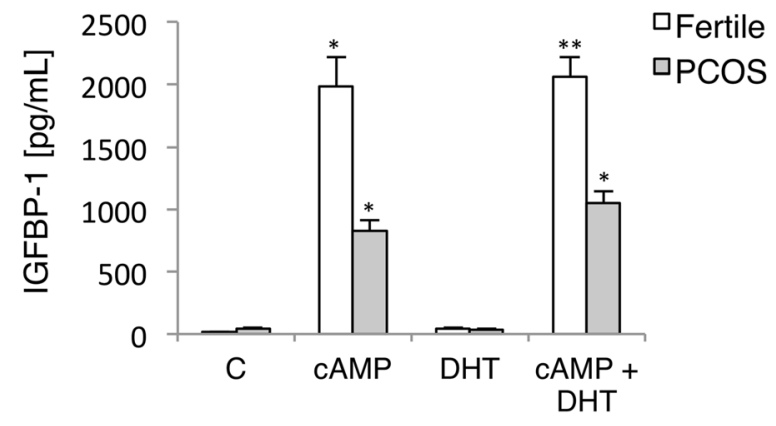

f

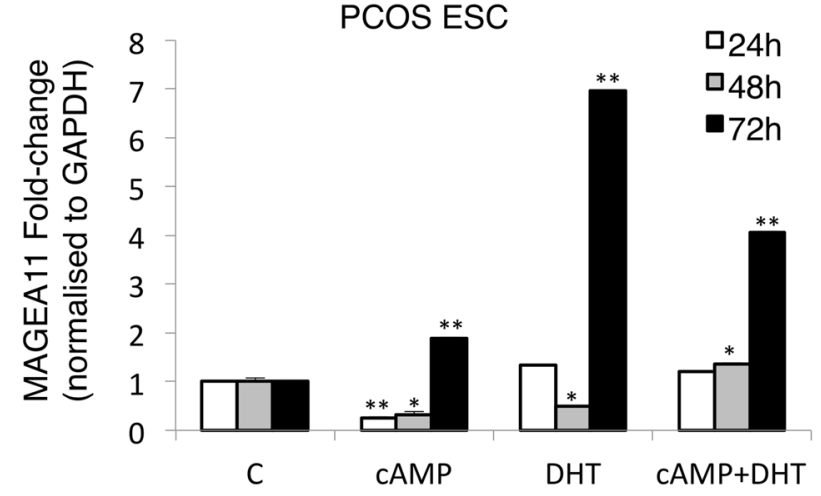

extracted after ESCs were isolated and treated for $48 \mathrm{~h}$. ELISA experiments were carried out on the conditioned media to establish the concentration of key proteins (prolactin/IGFBP-1) at the secreted level. Values were compared with their corresponding untreated cells. e, f After incubation, cell pellets were collected and RNA extracted to analyse MAGEA11 transcript levels by qRT-PCR. All values represent the average and standard deviation. Statistical analysis of the data was performed between samples of the same clinical sub-group using an ANOVA test followed by a $t$ test (treated vs untreated). ${ }^{*} p \leq 0.05$ and ${ }^{* *} p \leq 0.01$ were considered significant prolactin and IGFBP-1 following exposure to cAMP (prolactin: $p<0.01$; IGFBP-1: $p=0.035$ ) and cAMP + DHT (prolactin: $p=0.03$; IGFBP-1: $p=0.02$ ). These results are consistent with previous observations and indicate that the decidual response is either delayed or inhibited in PCOS patients. 


\section{In vitro response to DHT and cAMP treatments}

Steroids (DHT) and second messengers (cAMP) regulate the expression of the AR co-regulator MAGEA11 in human endometrial cell lines [11]. Accordingly, treatment of hESCs isolated from fertile samples with cAMP triggered a rapid and short-lived induction of MAGEA11 expression after $24 \mathrm{~h}$ (fold change $=1.9, p<0.01$ ), which decreased after $48 \mathrm{~h}$ and $72 \mathrm{~h}$ (Fig. 1e). For PCOS cells, the opposite response was observed, with MAGEA11 upregulation delayed until $72 \mathrm{~h}$ (fold change $=1.88 ; p<0.01$ ) (Fig. 1f). This delayed expression of MAGEA11 is consistent with previous observations, as the timing of maximal MAGEA11 mRNA expression in fertile women coincides with the window of receptivity to embryo implantation in the mid-secretory phase of the menstrual cycle [11], and thus suggests an anomalous decidual response in PCOS patients.

Cells were then treated with DHT, and in fertile hESC, MAGEA11 expression was significantly reduced at all time points $(24 \mathrm{~h}$ : fold change $=0.23, p<0.01 ; 48 \mathrm{~h}$ : fold change $=$ $0.24, p<0.01 ; 72 \mathrm{~h}$ : fold change $=0.48, p<0.01$ ), and when used in combination with cAMP, was further reduced after 48 and $72 \mathrm{~h}(48 \mathrm{~h}$ : fold change $=0.54, p<0.01 ; 72 \mathrm{~h}$ : fold change $=0.21, p<0.01)$ (Fig. 1e). This suggests that DHT through the action of AR, which is expressed at low levels in the mid-secretory phase of the menstrual cycle [11], represses normal MAGEA11 expression. In contrast, in PCOS
Fig. 3 MAGEA11 expression in secretory phase endometrium. Secretory phase endometrium from fertile $(n=33)$ and ovulatory PCOS (ovPCOS, $n=19)$ patients was analysed for the expression of MAGEA11/AR as described in the "Materials and Methods" section. a Inmunohistochemistry (IHC) figures showing MAGEA11/AR expression; IHC images display $\times 10$ magnification. Scale $=50 \mu \mathrm{m}$. b, d Analysis of the IHC scores (H-score) for MAGEA11 and AR antibodies. Fertile ( $n=33)$; ovPCOS $(n=19)$; E, epithelial; S, stromal. c, e RNA samples obtained from endometrial biopsies were analysed for the expression of MAGEA11/AR transcript levels as described in the "Materials and Methods" section. Fertile $(n=12)$; ovPCOS $(n=8)$. All values represent the median and inter-quartile range (box and whisker). Statistical analysis was performed using the Mann-Whitney $U$ test. ${ }^{*} p \leq$ 0.05 and $* * p \leq 0.01$ are considered significant

samples, there was a dramatic increase in MAGEA11 expression $72 \mathrm{~h}$ post-treatment (DHT: fold change $=7.03, p=0.01$; cAMP + DHT: fold change $=4.05, p=0.03$, Fig. 1f) indicating that MAGEA11 is positively regulated by DHT in PCOS stromal cells.

\section{Expression of MAGEA11 and AR in proliferative and secretory phase endometrial biopsies}

To determine whether the expression of MAGEA11 in vivo was similar to that observed in vitro, biopsies obtained from proliferative endometrium of fertile and PCOS patients were assessed using immunohistochemistry (IHC). a

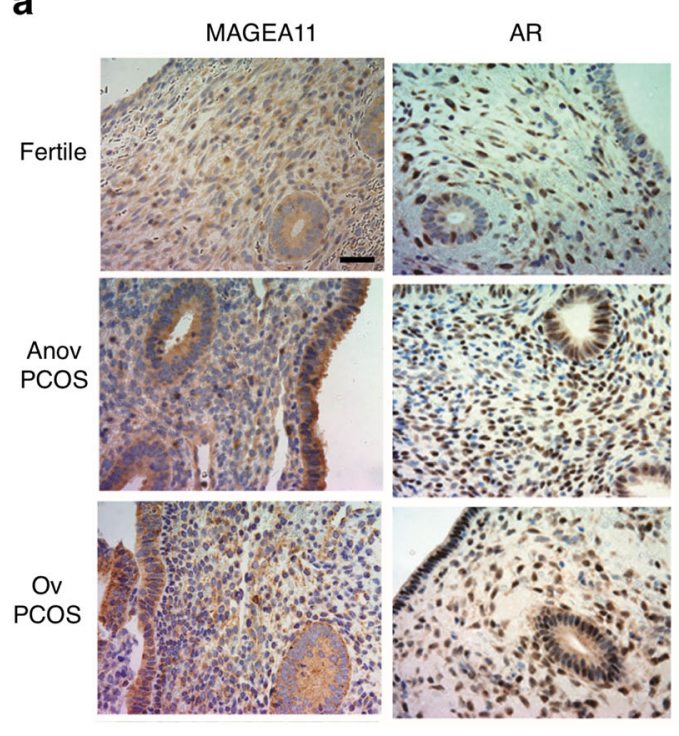

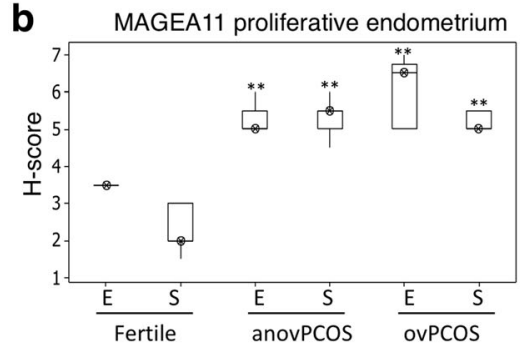

d

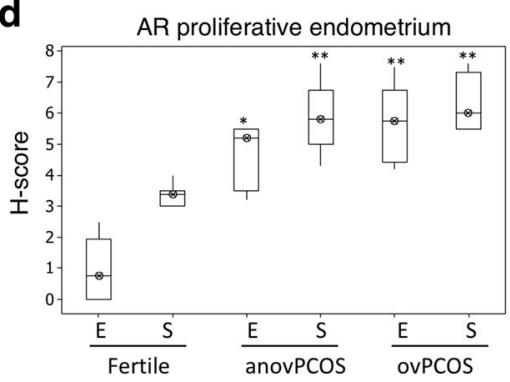

C

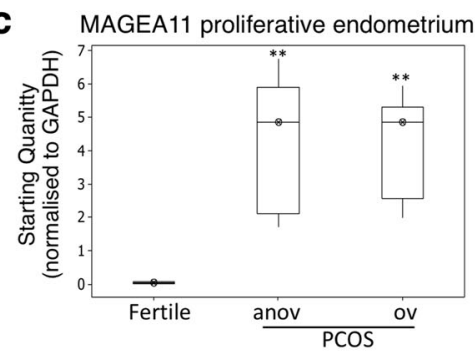

e

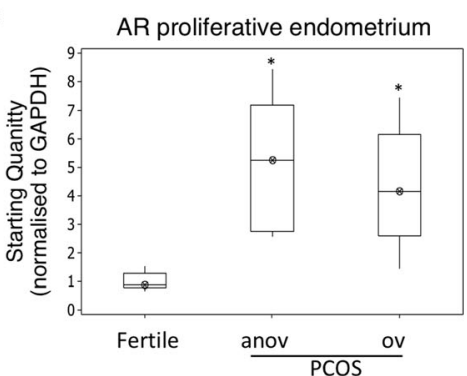

Fig. 2 MAGEA11 expression in proliferative phase endometrium. Proliferative phase endometrium from fertile, anovulatory PCOS and ovulatory PCOS patients was analysed for the expression of MAGEA11/AR as described in the "Materials and Methods" section. a Immunohistochemistry (IHC) figures showing MAGEA11/AR expression; IHC images display $\times 10$ magnification. Scale $=50 \mu \mathrm{m} . \mathbf{b}, \mathbf{d}$ Analysis of the IHC scores (H-score) for MAGEA11 and AR antibodies. Fertile $(n=18)$; anovulatory PCOS (anovPCOS, $n=21$ ); ovulatory
PCOS (ovPCOS, $n=25$ ); E, epithelial; S, stromal. c, e RNA samples obtained from endometrial biopsies were analysed for the expression of MAGEA11/AR transcript levels as described in the "Materials and Methods" section. Fertile $(n=10)$; anovPCOS [12]; ovPCOS $(n=6)$. All values represent median and inter-quartile ranges (box and whisker). Statistical analyses were performed using the Mann-Whitney $U$ test. * $p \leq$ 0.05 and $* * p \leq 0.01$ were considered significant 
a

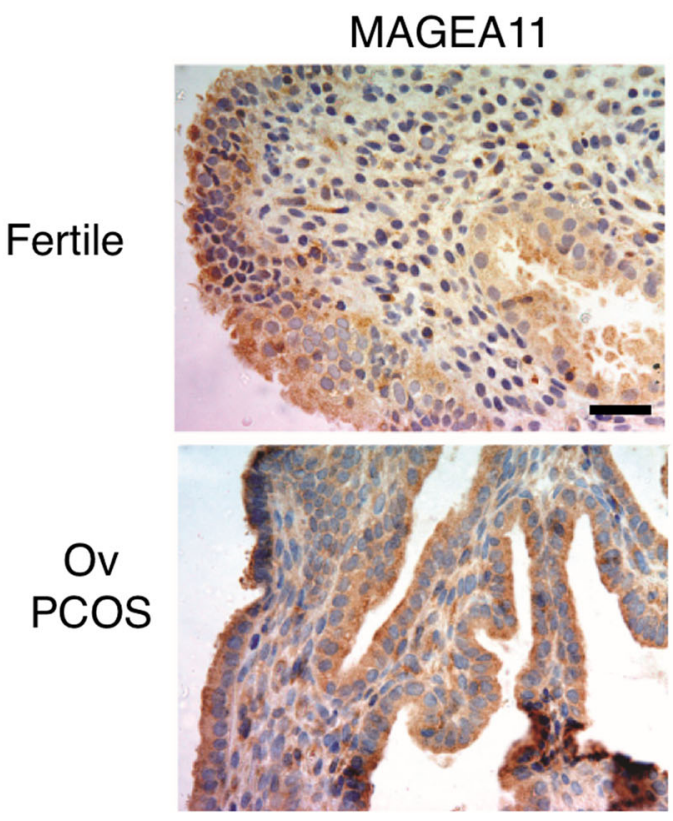

b

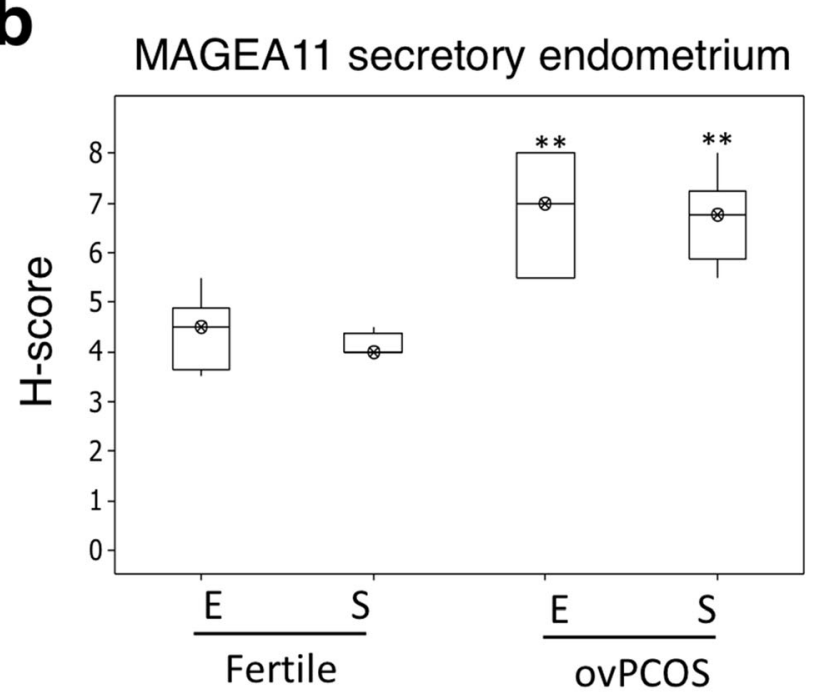

d

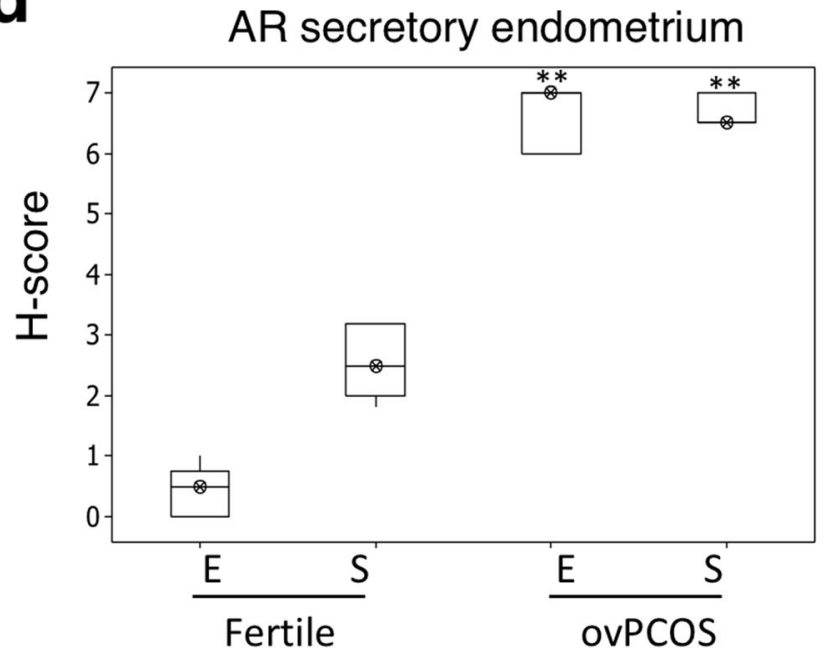

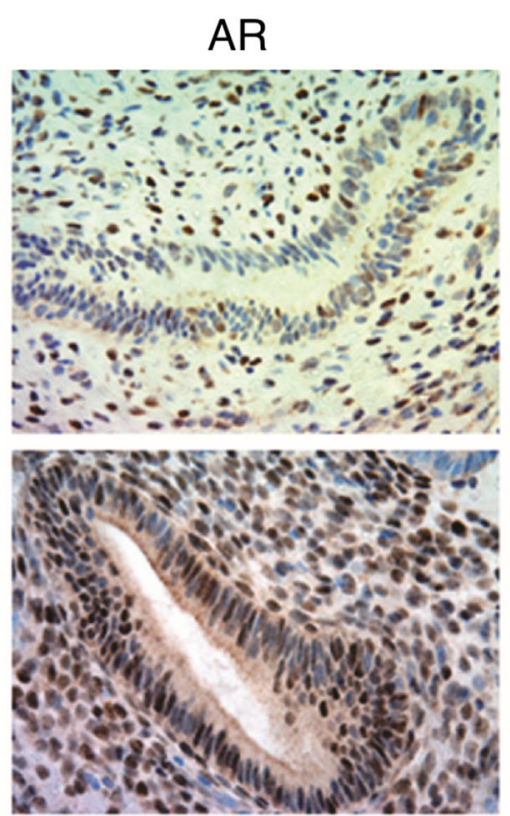

C

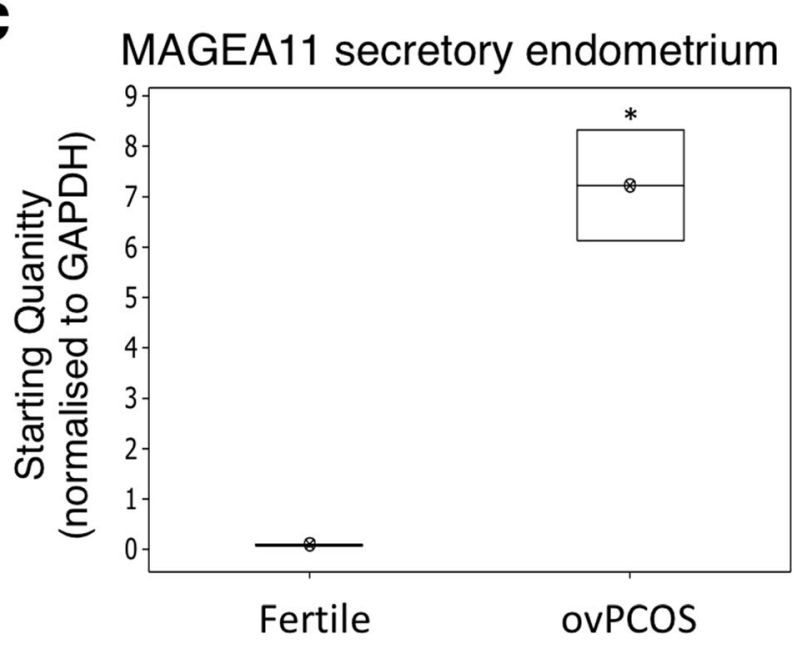

e

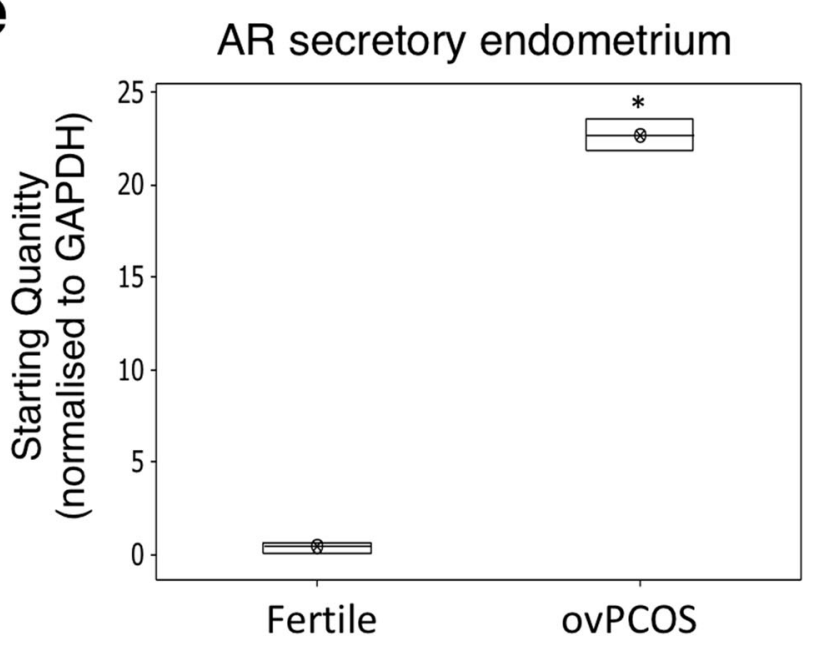


MAGEA11 was present in epithelial and stromal compartments of fertile endometrium, with expression restricted to the cytoplasm (Fig. 2a, b and Supplementary Fig. 2), and only low levels of MAGEA11 mRNA were detected in whole tissue extracts (Fig. 2c). Secretory phase expression was significantly higher in epithelial $(p=0.03)$ and stromal tissue $(p<0.01)$ compared with proliferative phase samples in fertile samples (Fig. 3a, b and Supplementary Fig. 2), confirming that MAGE11 expression is increased around the window of implantation [11]. Similarly, MAGEA11 mRNA expression showed an almost 3-fold increase in the secretory phase compared the proliferative phase in whole tissue samples (Fig. 3c, $p=0.01)$.

In ovulatory (ovPCOS) and anovulatory PCOS (anovPCOS), MAGEA11 levels were significantly higher than in fertile patients (Figs. 2 and 3 and Supplementary Fig. $2)$. Proliferative phase ovPCOS epithelial $(p<0.01)$ and stromal $(p<0.01)$ compartments showed high levels of expression, which were further increased in the secretory phase (epithelial and stromal $p<0.01)$. Similarly, MAGEA11 levels were significantly elevated in anovPCOS samples in both the epithelial $(p<0.01)$ and stromal $(p<0.01)$ compartments (Fig. 2a, b and Supplementary Fig. 2). MAGEA11 mRNA expression levels were significantly elevated in both ovPCOS (proliferative, $p=0.01$; secretory $p=0.05$ ) and anovPCOS $(p=0.0011)$ compared with fertile sample levels (Figs. 2c and 3c).

AR staining in fertile endometrium was higher during the proliferative phase of the cycle and predominantly expressed within the stromal compartment (Figs. $2 \mathrm{~d}$ and $3 \mathrm{~d}$ ). Consistent with other studies $[19,20]$, this suggests that in fertile endometrium, an increase in MAGEA11 is unlikely to be due to AR activity, as the two molecules are expressed in different phases of the menstrual cycle. In PCOS samples, AR staining (Figs. 2d and 3d) was higher compared with the fertile samples, and MAGEA11 and AR expression occurred concurrently throughout the cycle (Figs. 2e and 3e).

\section{MAGEA11 co-localises with AR in the nuclei of PCOS stromal cells}

Detailed analysis of AR and MAGEA11 distribution in PCOS samples revealed that they accumulate at high levels in both cytoplasmic and nuclear compartments (Figs. 2 and 3), whereas in cells from fertile patients, only low levels of AR and MAGEA11 staining were seen, and MAGEA11 was restricted to the cytoplasm. PCOS-specific nuclear co-localisation was also observed in vitro by confocal immunofluorescence microscopy when hESCs isolated from PCOS patients were treated with DHT (Fig. 4a and Supplementary Fig. 3). It appears that the two proteins could interact prior to nuclear importation, as per observed perinuclear or membraneassociated co-localisation (Fig. 4a and Supplementary Fig. 3).
Having demonstrated the temporal and spatial co-location of the two proteins, their direct molecular interaction was assessed, as such an interaction would support the notion that MAGEA11 functions as an AR nuclear co-regulator in the endometrial stroma, similar to its function in prostate cancer cells. Fertile and PCOS primary stromal cells were grown to confluence, and total protein extracted. Protein blot analysis revealed a major 50-kDa MAGEA11 isoform, corresponding to the canonical isoform one of the protein, which was expressed in both cell types (Fig. 4b). The bands observed in the $20-37-\mathrm{kDa}$ range could be a result of cross-reactivity with other MAGEA11 isoforms, as well as with a number of highly homologous MAGE proteins (e.g., MAGEA4, $34.7 \mathrm{kDa}$ ) [21]. Densitometry analysis demonstrated that canonical MAGEA11 expression was significantly greater in PCOS samples confirming IHC and cytometric analysis (Fig. 4b). Subsequently, the co-immunoprecipitation analysis was carried out in order to demonstrate any direct molecular interaction between MAGEA11 and AR. In PCOS stromal cells treated with $0.1 \mu \mathrm{M}$ DHT full-length $\sim 50 \mathrm{kDa}$ isoform one, MAGEA11 was detected at levels significantly above background (IgG), whereas no increase was observed in untreated cells (Fig. 4c). A second band ( $25 \mathrm{kDa})$ was detected as a result of co-immunoprecipitation (Fig. 4c), likely a product of the degradation of MAGEA11, which is known to have a short half-life [22]. These data demonstrate an association between native AR and MAGEA11 isolated from primary endometrial stromal cells, and given previous studies have shown that the MAGEA11-AR interaction has an absolute requirement for DHT, this suggests that such a complex would only form in PCOS patients with hyperandrogenaemia.

\section{Characterisation of AR targets in PCOS}

AR expression in PCOS stromal cells is likely to drive transcriptional re-programming and, as such, has a direct role in the delay of endometrial cell differentiation (Figs. 2 and 3 ). We therefore conducted genome-wide localisation experiments using chromatin immunoprecipitation coupled with DNA sequencing (ChIP-seq) to understand which transcriptional networks were likely to be regulated by AR. ChIP-seq chromatin isolated from DHT-treated PCOS hESCs probed with an anti-AR antibody identified 6296 loci (FDR 0.06\%) that were enriched for AR, with no $\mathrm{Y}$ chromosome representation (Table 2; Supplementary Table 1). The majority of AR binding occurred distal to the transcription start site, at distances between -500 and $-50 \mathrm{~kb}$ (Fig. 5a). To confirm the validity of the AR targets identified, we tested for the presence of consensus AR binding sites (RAACR) using the MEME software [24] and demonstrated that the nuclear receptor specifically recognised its cognate binding sequence $(p=3.85 \mathrm{E}-05)$ (Fig. $5 b)$. In addition, AR also 
Fig. 4 MAGEA11 protein localises to the nucleus of endometrial stromal cells and interacts with AR in PCOS patients. a Immunofluorescence confocal microscopy images of fertile and PCOS hESCs that were either left untreated (control, left panel) or treated with DHT for $48 \mathrm{~h}$ (DHT, right panel). ESCs were obtained from cells in the secretory phase of the cycle. Fixed cells were incubated with anti-AR and anti-MAGEA11 antibodies for detection. Scale $=$ $20 \mu \mathrm{m}$. b Cell lysates from fertile $(n=3)$ and PCOS $(n=3)$ ESCs were subjected to western blot analysis. The left panel shows a representative blot of MAGEA11 protein expression and the right panel displays the corresponding densitometry; values were normalised to GAPDH expression and are expressed as average and standard deviation (SD). The statistical analysis was performed using Student's $t$ test; * $p \leq 0.05$ is considered significant. c Cell lysates from PCOS ESCs were either left untreated (control, left panel) or treated with DHT for $24 \mathrm{~h}$ (right panel) and subjected to protein co-immuneprecipitation using an anti-AR antibody (N-20). Input was used as positive control and $\mathrm{IgG}$ as a negative control a

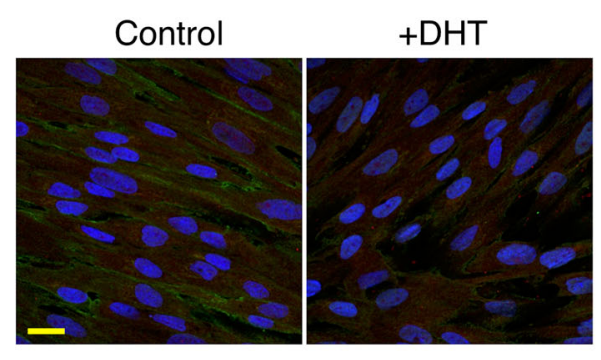

Fertile

b
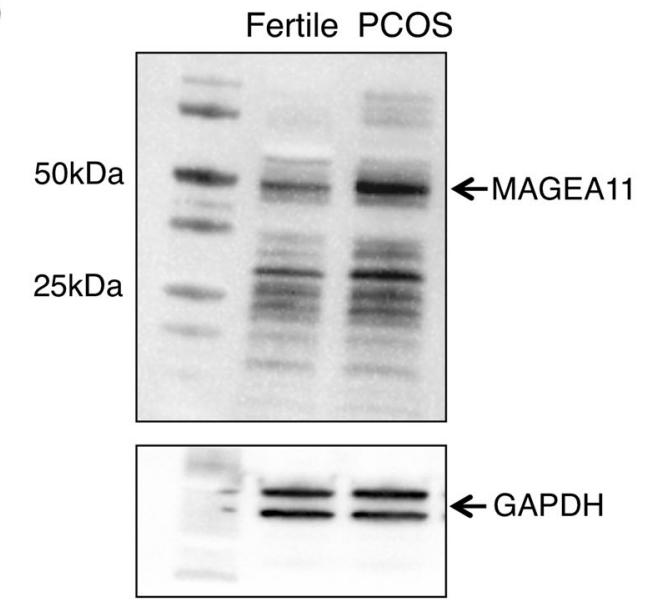

C

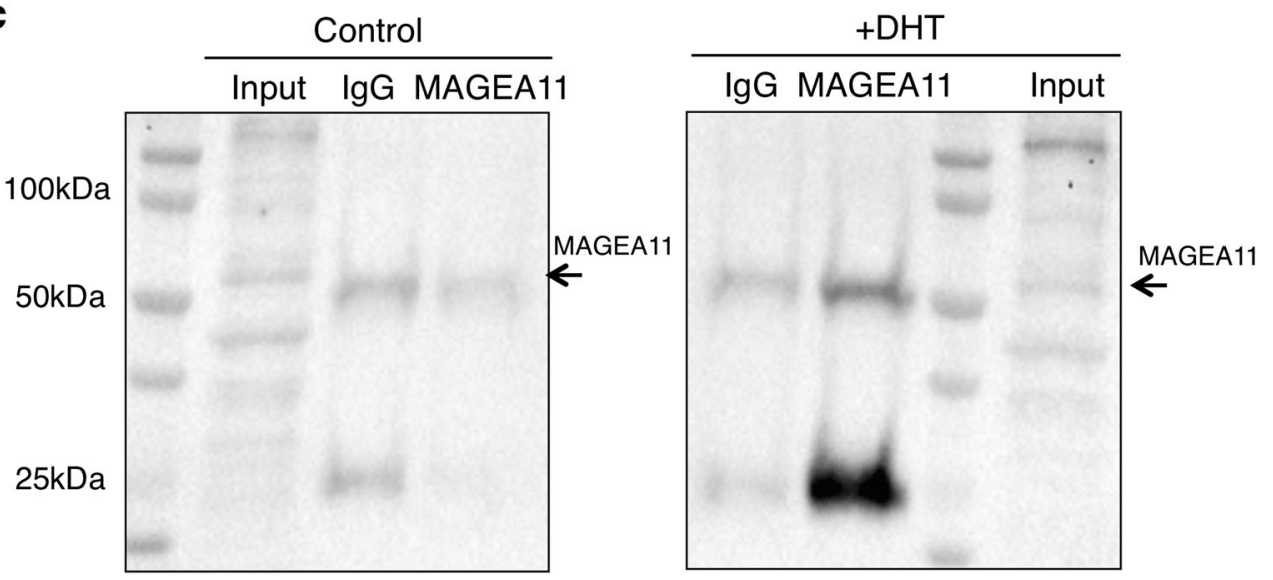

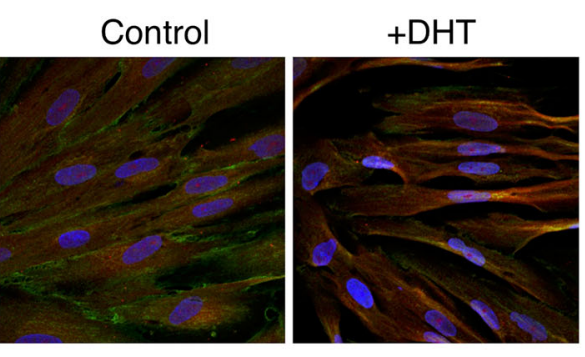

PCOS

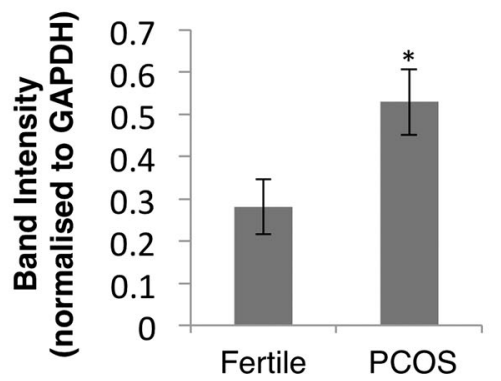

displayed highly specific recognition for JUN binding sites $(p=1.725 \mathrm{E}-07$, RTGAVTCA) and Sp1 (data not shown). JUN proteins are components of the AP-1 transcription activator family that have previously been shown to interact with, and enhance AR activity in prostate and prostate cancer cells $[25,26]$.

Gene ontology analysis revealed that AR targets were predominantly involved in processes related to the positive regulation of cell death, including apoptosis (Supplementary Table 2). This finding supports our early observations showing that apoptosis is delayed in PCOS, and suggests that the overexpression and hyperactivation of AR may be responsible for this. In addition, a number of specific AR targets including KLF9, KLF13, and PLZF were identified, all of which have roles in decidualisation [27, 28].

As AR functions predominately in male reproductive tissue, we asked whether the endometrial AR targets and regulatory pathways identified through our ChIP-seq analysis were tissue and gender-specific. Comparison of endometrial AR targets (577 genes) with AR targets from a prostate-specific data set (1371 genes) [23] revealed a set of targets that were specific to endometrial tissue (501 genes, Table 2), as well as a set of common AR targets (76 genes, Table 2). Common PCOSprostate targets include a number of genes involved in well- 
Table 2 Top androgen receptor targets in endometrial (PCOS) and castrate-resistant prostate cancer tissues

\begin{tabular}{|c|c|c|c|c|c|}
\hline \multicolumn{3}{|l|}{ PCOS specific } & \multicolumn{3}{|c|}{ Common PCOS-CRPC (prostate) } \\
\hline Symbol & Peak value & Accession No. & Symbol & Peak value & Accession No. \\
\hline DUSP27 & 130 & NM_001080426 & HFM1 & 185 & NM_001017975 \\
\hline MIR663 & 104 & NR_030386 & SLC25A44 & 153 & NM_014655 \\
\hline LOC100505875 & 100 & XR_112656 & PMF1 & 153 & NM_007221 \\
\hline LOC100506842 & 94 & XR_112632 & PDE3A & 114 & NM_000921 \\
\hline NFXL1 & 94 & NM_152995 & NLE1 & 109 & NM_001014445 \\
\hline MEF2D & 87 & NM_005920 & UNC45B & 109 & NM_173167 \\
\hline C14orf145 & 84 & NM_152446 & YEATS2 & 105 & NM_018023 \\
\hline TAF8 & 82 & NM_138572 & $\mathrm{ABCC} 5$ & 68 & NM_005688 \\
\hline ZRANB2 & 74 & NM_005455 & DNAJB12 & 54 & NM_001002762 \\
\hline PPM1D & 74 & NM_003620 & LRRFIP2 & 47 & NM_017724 \\
\hline TRIM56 & 74 & NM_030961 & PYGB & 45 & NM_002862 \\
\hline LTBP4 & 70 & NM_003573 & GTDC1 & 44 & NM_024659 \\
\hline ENTPD4 & 69 & NM_004901 & BATF & 40 & NM_006399 \\
\hline TOP & 64 & XR_109290 & C6orf81 & 40 & NM_145028 \\
\hline MIR1826 & 64 & NR_031727 & FAM105A & 39 & NM_019018 \\
\hline MMP19 & 63 & NM_002429 & BLK & 38 & NM_001715 \\
\hline RANBP3 & 63 & NM_007322 & RGS22 & 36 & NM_015668 \\
\hline C19orf45 & 63 & NM_198534 & ROCK1 & 35 & NM_005406 \\
\hline ZNF358 & 63 & NM_018083 & SOX13 & 34 & NM_005686 \\
\hline MCOLN1 & 63 & NM_020533 & KLF9 & 33 & NM_001206 \\
\hline
\end{tabular}

known carcinogenic processes such as Rho-GTPase signalling (ROCK1) [29] or the NF-K $\beta$ pathways (PYGB) [30], mechanisms commonly associated with the regulation of apoptosis. These findings indicate that AR targets are predominantly gender specific, although there is an overlap that highlights the connection between male and female reproductive malignancies.

Finally, as PCOS patients have an increased risk of developing endometrial cancer (EC), we considered whether any AR targets were implicated in this disease. Comparison of our data with a list of EC-related genes obtained from PubMed databases revealed a set of known oncogenic targets (16 genes, Fig. 5d), including tumour suppressor PTEN, whose expression is commonly lost in endometrial cancer tissues [31], the matrix metalloproteinase-2 (MMP2) and YAP1, which are commonly found overexpressed in endometrial cancers [32, 33]. Additionally, our comparisons identified the tumour suppressor gene WT1, whose expression is downregulated in PCOS endometrium during implantation [4].

\section{Discussion}

The window of implantation during the female reproductive cycle is a tightly controlled process, which if perturbed can result in the inability of the endometrium to receive and implant a blastocyst, and subsequently to establish the earliest phase of pregnancy. PCOS is a common multi-factorial disorder linked to female infertility. In women with PCOS symptoms who continue to ovulate, loss of normal endometrial function appears to be an underlying factor associated with infertility. Incorrect decidualisation, including timing and incomplete cellular transformation, can result in a non-receptive endometrium and incorrect intercellular signalling between the maternal tissue and the embryo.

A common feature of PCOS is elevated levels of circulating androgens - hyperandrogenaemia. This coincides with increased and temporally abnormal expression of the AR in endometrial tissue, which could lead to the activation of AR-driven transcriptional programmes. AR is a DNA-binding transcription factor, the function of which is to recruit co-regulator proteins to target genes resulting in either the activation or repression of the transcription of these targets. MAGEA11 has been described as a coactivator of AR in prostate tissues. Here, we show that the expression of MAGEA11 is increased in the endometrial stroma of PCOS tissue and cells isolated from this stromal compartment treated with DHT. This is a PCOS-specific effect, as MAGEA11 does not increase in the stromal component of endometrial tissue from fertile controls, nor does DHT treatment of cells derived from this tissue result in increased MAGEA11 expression. MAGEA11 protein was present as the canonical $50 \mathrm{kDa}$ isoform one in PCOS stromal cells, where it interacted directly with AR 

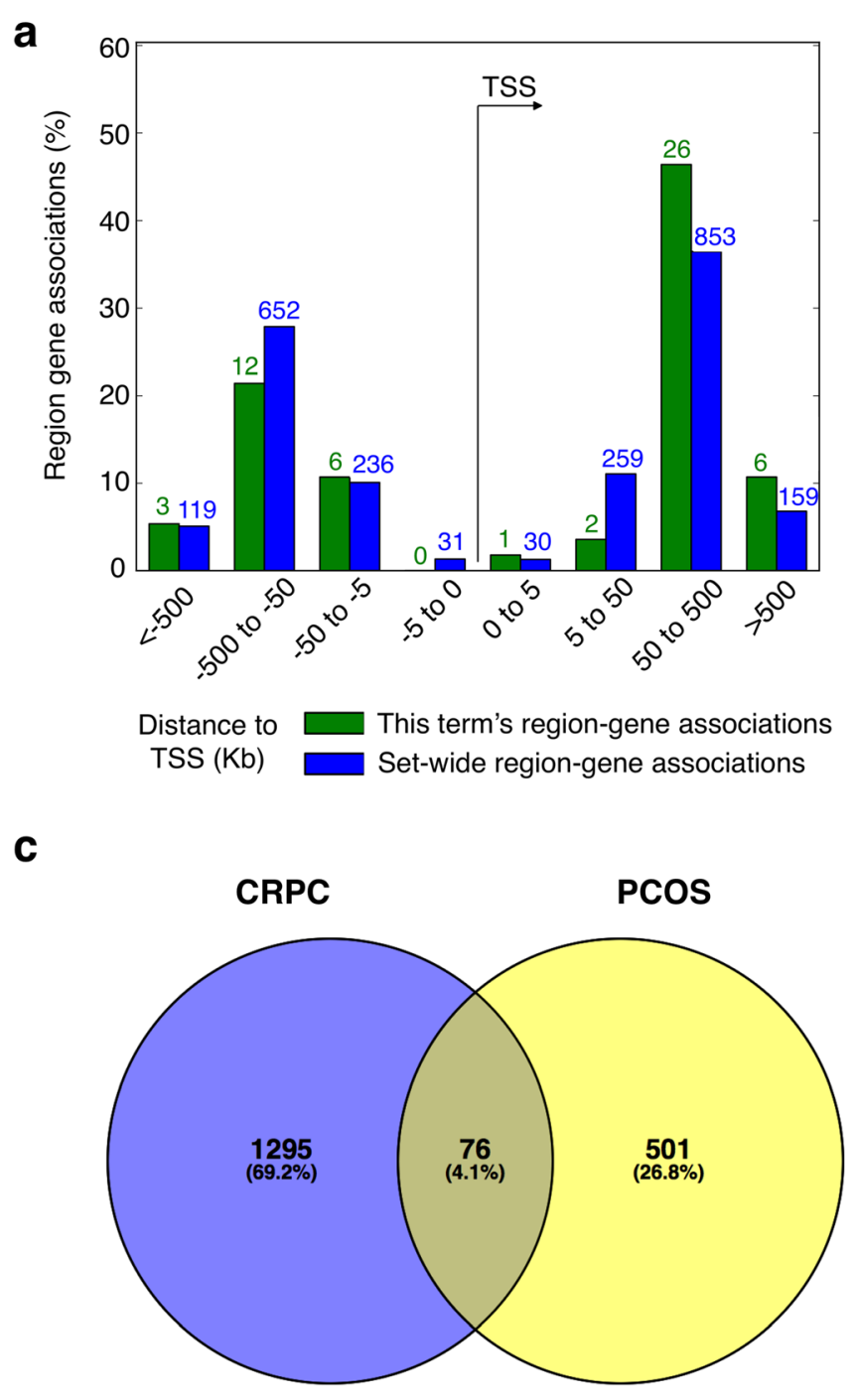

Fig. 5 Genome-wide analysis of AR targeting in PCOS stromal cells. a Diagram showing the average distribution of AR binding sites surrounding gene transcription starting sites (TSSs) in human PCOS tissue. This diagram was generated using the Genomic Regions Enrichment of Annotations Tool (GREAT). Blue columns represent the whole set of filtered AR peaks and green columns represent AR peaks directly linked to the PCOS disease, according to GREAT databases. b Sequence logos

in the presence of DHT. This is the first time this AR-MAGEA11 interaction has been demonstrated with native proteins isolated from primary endometrial cells and verifies that the ARMAGEA11 interaction previously shown using overexpressed proteins isolated from mammalian expression systems is indeed physiologically relevant.

AR chromatin immunoprecipitation experiments using PCOS stromal cells stimulated with DHT identified the direct targets of the nuclear hormone receptor. Krüppel-like factor (KLF)-9 and 13 transcription factors (KLF9/KLF13) were both major AR targets as determined by the depth of read. KLF9 is expressed in endometrial stromal cells but controls the response b
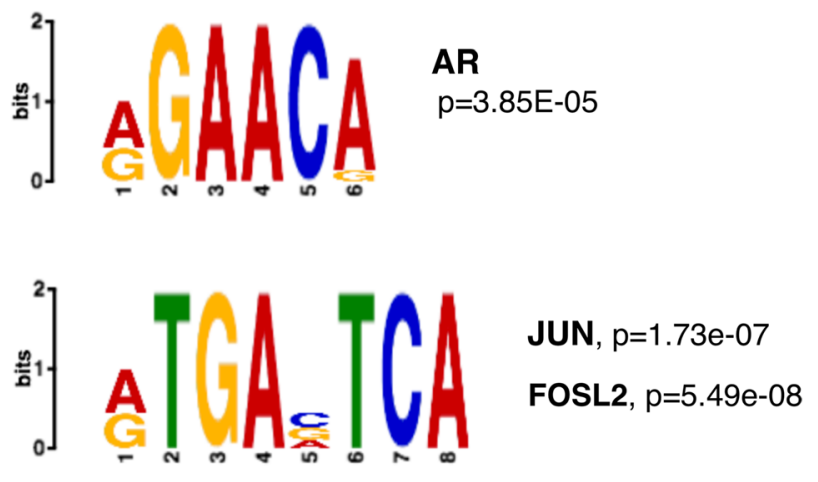

d

\begin{tabular}{cc} 
SYMBOL & Accession No. \\
\hline YAP1 & NM_001130145 \\
IGF1 & NM_000618 \\
FOXO1 & NM_002015 \\
LEPR & NM_002303 \\
IRS2 & NM_003749 \\
CYR61 & NM_001554 \\
FTO & NM_001080432 \\
MMP2 & NM_004530 \\
STAT3 & NM_139276 \\
TGFBR3 & NM_003243 \\
MIR21 & NR_029493.1 \\
MIR155 & NR_030784.1 \\
PPARG & NM_138712 \\
AR & NM_000044 \\
PTEN & NM_000314 \\
WT1 & NM_000378
\end{tabular}

and correspondent $p$ values of transcription factor binding motifs enriched for AR in human PCOS tissue, generated with the MEME-Suite application. c Venn diagram showing the overlap between AR binding sites identified in human PCOS tissue and castrate-resistant prostate cancer (CRPC) [23]. d Table containing the list of genes identified as targets of AR in PCOS tissue, which are also involved in endometrial cancer disease, according to the NCBI databases

of adjacent luminal epithelial cells to progesterone [27]. In murine models, loss of klf9 results in less post-implantation embryos, which appears to be due to increased levels of BMP2 in these animals. In hESC treated with cAMP, estradiol-17 $\beta$ (E2) and medroxyprogesterone acetate to induce decidualisation, as well as siRNA to knock down KLF9 expression, both KLF13 and BMP2 mRNA levels increase. Conversely, in the same decidualised hESC model, siRNA to knock down KLF13 results in the increase of KLF9 expression and reduction of BMP2. This KLF-BMP appears important as the endometrial stromal cells of $b m p 2$-deleted mice are infertile [27]. Disruption of this signalling axis by AR binding to KLF9 and 13 could 
therefore be a cause of delayed/failed decidualisation in PCOS patients. The promyelocytic leukaemia zinc finger transcription factor (PLZF) was a second transcription factor identified as a direct AR target. PLZF appears to have a role in P4-dependant $\mathrm{hESC}$ decidualisation as it is normally induced by $\mathrm{P} 4$ and contains PR regulator regions, and controls EGR1 expression levels [28]. KLF9/13 and PLZF normally function through the PR transcription pathway. It appears overexpression and activation of AR could disrupt this normal high-level transcriptional programming via driving misexpression of these key transcriptional regulators in PCOS patients.

Interestingly, as well as binding to AR response elements, the nuclear receptor is also recruited to JUN response elementcontaining regulatory regions, presumably by a JUN response element-binding protein such as c-Jun, which interacts directly with AR in prostate cancer cells and enhances the transactivation function of AR $[25,26]$.

Gene ontology analysis of AR chromatin immunoprecipitation data revealed that AR interacts with genes involved in the regulation of cell death and apoptosis including EGFR and WT1, the expression of which is reduced in PCOS [4], suggesting AR may act as a repressor at the WT1 locus. The consequences of this repression have been highlighted before [4] and substantiate a functional role of AR in decidualisation. Bcl2, a known WT1 target, becomes upregulated in PCOS patients following AR activation, delaying the cell cycle and inhibiting apoptosis via p27 [34]. $\beta$-catenin, repressed by WT1 in fertile cells [35], is expressed in PCOS women, and likely contributes to the abnormal upregulation of the Wnt pathway $[4,36]$. The impact of AR targeting these genes appears to be manifested in the delayed and incomplete morphological transition of stromal cells isolated from PCOS endometrium where cells retain a more elongated mesenchymallike phenotype and produce a limited amount of prolactin when treated with the decidualisation stimulus of cAMP.

Together, these data support the notion that elevated androgens result in delayed decidualisation and implicate AR and its co-regulator MAGEA11 in incorrect endometrial differentiation, the critical timing process of embryo implantation, and thus human reproduction.

Author contributions K.Y carried out experiments and contributed to manuscript preparation. M.Q performed data analysis and contributed to manuscript preparation. S.T, J.G, L.B, and H.W performed experiments and carried out statistical analyses. A.B and L.M collected materials and clinical data. L.F, L.M, and D.G contributed to study conception and design, interpretation of data, manuscript preparation, and critical revision. R.S.C study conception and design, supervised the findings, and drafted the manuscript.

\section{Compliance with ethical standards}

Conflict of interest The authors declare that they have no conflict of interest.
Ethics statement Ethical approval was obtained from the South West Wales Research Ethics Committee (LREC05/WMW02/103 and 12/WA/ 0298).।

Statement of informed consent Formal written consent was obtained from all patients at the time of recruitment.

Open Access This article is distributed under the terms of the Creative Commons Attribution 4.0 International License (http:// creativecommons.org/licenses/by/4.0/), which permits unrestricted use, distribution, and reproduction in any medium, provided you give appropriate credit to the original author(s) and the source, provide a link to the Creative Commons license, and indicate if changes were made.

\section{References}

1. Jakimiuk AJ, Weitsman SR, Brzechffa PR, Magoffin DA (1998) Aromatase mRNA expression in individual follicles from polycystic ovaries. Mol Hum Reprod 4(1):1-8

2. Laven JSE, Imani B, Eijkemans MJC, Fauser BCJM (2002) New approach to polycystic ovary syndrome and other forms of anovulatory infertility. Obstet Gynecol Surv 57(11):755-767

3. Okada H, Tsuzuki T, Murata H (2018) Decidualization of the human endometrium. Reprod Med Biol 17(3):220-227

4. Gonzalez D, Thackeray H, Lewis PD, Mantani A, Brook N, Ahuja K, Margara R, Joels L, White JO, Conlan RS (2012) Loss of WT1 expression in the endometrium of infertile PCOS patients: a hyperandrogenic effect? J Clin Endocrinol Metab 97(3):957-966

5. Davey RA, Grossmann M (2016) Androgen receptor structure, function and biology: from bench to bedside. Clin Biochem Rev 37(1):3-15

6. Bai S, He B, Wilson EM (2005) Melanoma antigen gene protein MAGE-11 regulates androgen receptor function by modulating the interdomain interaction. Mol Cell Biol 25(4):1238-1257

7. Su S, Blackwelder AJ, Grossman G, Minges JT, Yuan L, Young SL, Wilson EM (2012) Primate-specific melanoma antigen-A11 regulates isoform-specific human progesterone receptor-B transactivation. J Biol Chem 287(41):34809-34824

8. Gjerstorff MF, Harkness L, Kassem M, Frandsen U, Nielsen O, Lutterodt M, Møllgård K, Ditzel HJ (2008) Distinct GAGE and MAGE-A expression during early human development indicate specific roles in lineage differentiation. Hum Reprod 23(10): 2194-2201

9. Yang B, O'Herrin S, Wu J, Reagan-Shaw S, Ma Y, Nihal M et al (2007) Select cancer testes antigens of the MAGE-A, -B, and -C families are expressed in mast cell lines and promote cell viability in vitro and in vivo. J Invest Dermatol 127(2):267-275

10. Peikert T, Specks U, Farver C, Erzurum SC, Comhair SAA (2006) Melanoma antigen A4 is expressed in non-small cell lung cancers and promotes apoptosis. Cancer Res 66(9):4693-4700

11. Bai S, Grossman G, Yuan L, Lessey BA, French FS, Young SL, Wilson EM (2008) Hormone control and expression of androgen receptor coregulator MAGE-11 in human endometrium during the window of receptivity to embryo implantation. Mol Hum Reprod 14(2):107-116

12. Askew EB, Bai S, Blackwelder AJ, Wilson EM (2010) Transcriptional synergy between melanoma antigen gene proteinA11 (MAGE-11) and p300 in androgen receptor signaling. J Biol Chem 285(28):21824-21836

13. Dimitriadis E, Robb L, Salamonsen LA (2002) Interleukin 11 advances progesterone-induced decidualization of human endometrial stromal cells. Mol Hum Reprod 8(7):636-643

14. Pan-Castillo B, Gazze SA, Thomas S, Lucas C, Margarit L, Gonzalez D, Francis LW, Conlan RS (2018) Morphophysical 
dynamics of human endometrial cells during decidualization. Nanomed Nanotechnol Biol Med 14:2235-2245

15. Welt CK, Gudmundsson JA, Arason G, Adams J, Palsdottir H, Gudlaugsdottir G, Ingadottir G, Crowley WF (2006) Characterizing discrete subsets of polycystic ovary syndrome as defined by the Rotterdam criteria: the impact of weight on phenotype and metabolic features. J Clin Endocrinol Metab 91(12):48424848

16. Margarit L, Taylor A, Roberts MH, Hopkins L, Davies C, Brenton AG, Conlan RS, Bunkheila A, Joels L, White JO, Gonzalez D (2010) MUC1 as a discriminator between endometrium from fertile and infertile patients with PCOS and endometriosis. J Clin Endocrinol Metab 95(12):5320-5329

17. Zhang X-H, Liang X, Liang X-H, Wang T-S, Qi Q-R, Deng W-B, Sha AG, Yang ZM (2013) The mesenchymal-epithelial transition during in vitro decidualization. Reprod Sci 20(4):354-360

18. Tiryaki VM, Adia-Nimuwa U, Ayres VM, Ahmed I, Shreiber DI (2015) Texture-based segmentation and a new cell shape index for quantitative analysis of cell spreading in AFM images. Cytometry A 87(12):1090-1100

19. Apparao KBC, Lovely LP, Gui Y, Lininger RA, Lessey BA (2002) Elevated endometrial androgen receptor expression in women with polycystic ovarian syndrome. Biol Reprod 66(2):297-304

20. Rae M, Mohamad A, Price D, Hadoke PWF, Walker BR, Mason JI, Hillier SG, Critchley HOD (2009) Cortisol inactivation by $11 \beta$ hydroxysteroid dehydrogenase-2 may enhance endometrial angiogenesis via reduced thrombospondin-1 in heavy menstruation. $\mathrm{J}$ Clin Endocrinol Metab 94(4):1443-1450

21. Weon JL, Potts PR (2015) The MAGE protein family and cancer. Curr Opin Cell Biol 37:1-8

22. Bai S, Wilson EM (2008 Mar 15) Epidermal-growth-factordependent phosphorylation and ubiquitinylation of MAGE-11 regulates its interaction with the androgen receptor. Mol Cell Biol 28(6):1947-1963

23. Sharma NL, Massie CE, Ramos-Montoya A, Zecchini V, Scott HE, Lamb AD, MacArthur S, Stark R, Warren AY, Mills IG, Neal DE (2013 Jan) The androgen receptor induces a distinct transcriptional program in castration-resistant prostate cancer in man. Cancer Cell 23(1):35-47

24. Bailey TL, Williams N, Misleh C, Li WW (2006) MEME: discovering and analyzing DNA and protein sequence motifs. Nucleic Acids Res 34(Web Server):W369-W373

25. Bubulya A, Wise SC, Shen XQ, Burmeister LA, Shemshedini L (1996) c-Jun can mediate androgen receptor-induced transactivation. J Biol Chem 271(40):24583-24589

26. Chen S-Y, Cai C, Fisher CJ, Zheng Z, Omwancha J, Hsieh C-L, Shemshedini L (2006) c-Jun enhancement of androgen receptor transactivation is associated with prostate cancer cell proliferation. Oncogene. 25(54):7212-7223
27. Pabona JMP, Zeng Z, Simmen FA, Simmen RCM (2010) Functional differentiation of uterine stromal cells involves crossregulation between bone morphogenetic protein 2 and Krüppel-like factor (KLF) family members KLF9 and KLF13. Endocrinology. 151(7):3396-3406

28. Kommagani R, Szwarc MM, Vasquez YM, Peavey MC, Mazur EC, Gibbons WE, Lanz RB, DeMayo FJ, Lydon JP (2016) The promyelocytic leukemia zinc finger transcription factor is critical for human endometrial stromal cell decidualization. Spencer TE, editor. PLoS Genet 12(4):e1005937

29. Liu K, Li X, Wang J, Wang Y, Dong H, Li J (2017) Genetic variants in RhoA and ROCK1 genes are associated with the development, progression and prognosis of prostate cancer. Oncotarget. 8(12): 19298-19309

30. Wang Z, Han G, Liu Q, Zhang W, Wang J (2018) Silencing of PYGB suppresses growth and promotes the apoptosis of prostate cancer cells via the NF- $\mathrm{kB} / \mathrm{Nrf} 2$ signaling pathway. Mol Med Rep. 2018;18(4):3800-8

31. Yang HP, Meeker A, Guido R, Gunter MJ, Huang GS, Luhn P, d'Ambrosio L, Wentzensen N, Sherman ME (2015) PTEN expression in benign human endometrial tissue and cancer in relation to endometrial cancer risk factors. Cancer Causes Control 26(12): $1729-1736$

32. Tsujiura M, Mazack V, Sudol M, Kaspar HG, Nash J, Carey DJ, Gogoi R (2014) Yes-associated protein (YAP) modulates oncogenic features and radiation sensitivity in endometrial cancer. Wanjin $\mathrm{H}$, editor. PLoS One 9(6):e100974

33. Liu C, Li Y, Hu S, Chen Y, Gao L, Liu D, Guo H, Yang Y (2018) Clinical significance of matrix metalloproteinase-2 in endometrial cancer: a systematic review and meta-analysis. Medicine (Baltimore) 97(29):e10994

34. Janumyan Y, Cui Q, Yan L, Sansam CG, Valentin M, Yang E (2008) G0 function of BCL2 and BCL-x L requires BAX, BAK, and p27 phosphorylation by mirk, revealing a novel role of BAX and BAK in quiescence regulation. J Biol Chem 283(49):3410834120

35. Kim MS, Yoon SK, Bollig F, Kitagaki J, Hur W, Whye NJ, Wu YP, Rivera MN, Park JY, Kim HS, Malik K, Bell DW, Englert C, Perantoni AO, Lee SB (2010 May 7) A novel Wilms tumor 1 (WT1) target gene negatively regulates the WNT signaling pathway. J Biol Chem 285(19):14585-14593

36. Savaris RF, Groll JM, Young SL, DeMayo FJ, Jeong J-W, Hamilton AE et al (2011 Jun) Progesterone resistance in PCOS endometrium: a microarray analysis in clomiphene citrate-treated and artificial menstrual cycles. J Clin Endocrinol Metab 96(6):1737-1746

Publisher's note Springer Nature remains neutral with regard to jurisdictional claims in published maps and institutional affiliations. 